\title{
Gear Crack Level Classification Based on EMD and EDT
}

\author{
Haiping Li, ${ }^{1}$ Jianmin Zhao, ${ }^{1}$ Xinghui Zhang, ${ }^{1}$ and Hongzhi Teng ${ }^{1,2}$ \\ ${ }^{1}$ The Sixth Department, Mechanical Engineering College, No. 97 Heping West Road, Xinhua District, Shijiazhuang, \\ Hebei 050003, China \\ ${ }^{2}$ Lanzhou Maintenance Centre, No. 27 Fanjiaping Road, Xigu District, Lanzhou, Gansu 730060, China
}

Correspondence should be addressed to Jianmin Zhao; jm_zhao@hotmail.com

Received 3 July 2014; Accepted 27 October 2014

Academic Editor: Wenbin Wang

Copyright (C) 2015 Haiping Li et al. This is an open access article distributed under the Creative Commons Attribution License, which permits unrestricted use, distribution, and reproduction in any medium, provided the original work is properly cited.

\begin{abstract}
Gears are the most essential parts in rotating machinery. Crack fault is one of damage modes most frequently occurring in gears. So, this paper deals with the problem of different crack levels classification. The proposed method is mainly based on empirical mode decomposition (EMD) and Euclidean distance technique (EDT). First, vibration signal acquired by accelerometer is processed by EMD and intrinsic mode functions (IMFs) are obtained. Then, a correlation coefficient based method is proposed to select the sensitive IMFs which contain main gear fault information. And energy of these IMFs is chosen as the fault feature by comparing with kurtosis and skewness. Finally, Euclidean distances between test sample and four classes trained samples are calculated, and on this basis, fault level classification of the test sample can be made. The proposed approach is tested and validated through a gearbox experiment, in which four crack levels and three kinds of loads are utilized. The results show that the proposed method has high accuracy rates in classifying different crack levels and may be adaptive to different conditions.
\end{abstract}

\section{Introduction}

Gearboxes are one of the fundamental and important components of rotating machinery. Its function is to transfer torque and power from one shaft to another. Representative applications involve motorcars, helicopters, and steel mills. Their failures will lead to great power loss and high maintenance fee. Therefore, condition monitoring and fault diagnosis of gearboxes are important topics in maintenance field.

Jardine et al. [1] summarized and reviewed the research and developments in diagnostics and prognostics of mechanical systems. They mainly focused on models, algorithms, and technologies of data processing and maintenance decisionmaking. Samuel and Pines [2] reviewed vibration-based diagnosis techniques for helicopter transmission system. The importance of condition monitoring for gearbox was emphasized from cost and safety point of view. In addition, features used for fault diagnosis and remaining useful lifetime prediction were introduced. Meanwhile, various fault detection methods of gearbox were discussed. Lebold et al. [3] reviewed feature extraction methods for gearbox diagnosis and prognosis. Samuel and Pines [4] and McFadden [5, 6] separated the vibration signal of planet and sun gears using time domain averaging. Halim et al. [7] combined time synchronous average and wavelet transformation together to extract periodic waveforms at different scales from noisy vibration signals to clean up noise and detect both local and distributed faults simultaneously. Feng et al. [8] proposed a regularization dimension technique to make vibration signals increase monotonically with respect to gear fault levels. Zhang et al. $[9,10]$ used narrow band interference cancellation to enhance the gearbox fault diagnosis and extract effective degradation indicator which is not sensitive to the nonstationary condition. In addition, many other techniques have been used in fault diagnosis of gearboxes, such as support vector machine (SVM) [11, 12], wavelet packet transformation (WPT) [13], artificial neural network (ANN) [14], and hidden Markov model (HMM) [15-17].

For gearbox fault diagnosis, fault level classification is more difficult than fault detection. However, limited papers reported research topic about different fault levels identification. Typical faults of gears include pitting, chipping, and crack $[18,19]$. In particular for gear crack fault, it is difficult to diagnose. Loutridis $[19,20]$ utilized instantaneous energy 
density and local scaling exponent algorithm to detect gear crack and identify crack levels effectively. Lei and Zuo [21] proposed a gear crack level identification method based on weighted KNN classification algorithm. However, the above methods require the expertise of an engineer to apply them successfully. A dilemma of crack level classification is early fault detection. This is a challenge to traditional method. Taking frequency spectrum analysis as an example, it is based on the amplitude changing of fault characteristic frequency. Due to the fact that the amplitude changing is not very large between early fault and normal condition, the phenomenon is not obvious in its frequency spectrum and it is very difficult to detect the early fault. However, the minor changing can be reflected in an IMF obtained using EMD. Then the changing will be very obvious after being amplified by IMF. Thus, EMD is very adaptive to early fault detection of gearbox. In addition, EDT is a useful method to help in automotive fault diagnosis and fault level classification. Therefore, this paper proposed a fault level classification method based on EMD and EDT, which has a good performance in early gear crack fault. A correlation coefficient based method is also proposed to select the sensitive IMFs which contain main gear fault information. By comparing with kurtosis and skewness, it is found that energy of these IMFs is the most suitable feature to be used in fault level classification. The effectiveness of the proposed method has been validated through analyzing gearbox experimental data.

The remaining sections of this paper are organized as follows. In Section 2, framework of the proposed gear crack level classification method is given. Section 3 describes the experiment and applies the proposed method to fault level diagnosis. Finally, conclusions are given in Section 4.

\section{Framework of the Proposed Method}

Hilbert Huang transform (HHT) is a new signal processing method developed by Huang et al. [22]. It contains two parts: EMD and Hilbert spectrum analysis method. As the kernel of HHT, EMD has been developed and widely used in fault diagnosis of rotating machinery recently [23-26]. Using EMD, the complex signal can be decomposed into a set of complete, simple, and almost orthogonal components named intrinsic mode functions (IMFs). The IMFs represent the natural oscillatory mode embedded in the signal and work as the basis functions, which are determined by the signal itself. And the IMFs should satisfy the following two conditions: (1) in the whole data set, the number of extrema and the number of zero-crossings must either be equal or differ at most by one and (2) at any point, the mean value of the envelope defined by local maxima and minima must be zero. Namely, local signal is symmetrical about the time axis.

EMD is developed based on the assumption that any signal consists of many different IMFs. The procedures of decomposing a given signal $x(t)$ to different IMFs can be categorized into the following steps. First, identify all the local extrema from the given signal and then connect them with a cubic spline line as the upper envelope $l_{\max }(t)$. Second, repeat the first step for the local minima to produce the lower envelope $l_{\min }(t)$. The upper and lower envelopes should cover the entire signal between them. Third, compute their mean as $m_{1}(t)$ and the difference between the signal $x(t)$ and $m_{1}(t)$ is $h_{1}(t)$. Consider

$$
\begin{aligned}
& m_{1}(t)=\frac{l_{\max }(t)+l_{\min }(t)}{2}, \\
& h_{1}(t)=x(t)-m_{1}(t) .
\end{aligned}
$$

Ideally, after the sifting operation of $(1), h_{1}(t)$ should be the first IMF. The construction of $h_{1}(t)$ described above seems to satisfy all the requirements of IMF. However, during the practical process, the theoretical upper envelope $l_{\max }(t)$ and lower envelope $l_{\min }(t)$ are very difficult to calculate. In addition, any little inflection points of the monotonous signal can be transformed to new extrema. And these new extremas should be contained by the next sifting operation. To solve this dilemma, Huang et al. [22] repeated the sifting process of (1) as many times as required to reduce the extracted signal to an IMF. Therefore, the fourth step is to repeat the sifting process by treating $h_{1}(t)$ as the original signal as follows:

$$
\begin{aligned}
m_{11}(t) & =\frac{l_{1 \max }(t)+l_{1 \min }(t)}{2}, \\
h_{11}(t) & =h_{1}(t)-m_{11}(t) .
\end{aligned}
$$

The sifting process will be repeated $k$ times until $h_{1 k}(t)$ becomes a true IMF; that is,

$$
h_{1 k}(t)=h_{1(k-1)}(t)-m_{1(k-1)}(t) .
$$

Then, make $c_{1}(t)=h_{1 k}(t)$, and it can be seemed as the first IMF. Remove $c_{1}(t)$ from the signal $x(t)$; namely,

$$
r_{1}(t)=x(t)-c_{1}(t) .
$$

And generate the residue signal $r_{1}(t)$. Treating $r_{1}(t)$ as a new original signal and repeating the same sifting process above, the second IMF can be getted. Similarly, a series of IMFs $\left(c_{i}(t)(i=1,2, \ldots, n)\right)$ can be obtained until the final residue $r_{n}(t)$ is monotonous. Then the original signal $x(t)$ can be reconstructed as

$$
x(t)=\sum_{i=1}^{n} c_{i}(t)+r_{n}(t) .
$$

The IMFs $c_{1}, c_{2}, \ldots, c_{n}$ represent different frequency bands ranging from high to low. The frequency components contained in each frequency band are different and they change with the variation of the original signal $x(t)$, and $r_{n}(t)$ represents the central tendency of signal $x(t)$.

After getting all the IMFs of a signal, sensitive IMFs which contain main fault information should be selected to promote the velocity of calculation. This paper proposed a correlation coefficient based method to select sensitive IMFs, as follows.

(1) Assume one test sample of fault state $x_{\text {fault }}(t)$ produced $K$ IMFs $c_{k}(t)(k=1,2, \ldots, K)$ after being processed by EMD; compute the correlation coefficients $\alpha_{k}$ of $c_{k}(t)$ and $x_{\text {fault }}(t)$. 
(2) Similarly, compute the correlation coefficients $\beta_{k}$ of $c_{k}(t)$ and $x_{\text {normal }}(t)$.

(3) Calculate the fault factors $\lambda_{k}$ based on $\alpha_{k}$ and $\beta_{k}$; namely,

$$
\lambda_{k}=\alpha_{k}-\beta_{k}, \quad(k=1,2, \ldots, K) .
$$

(4) Analyze the fault factors and select the $P$ bigger value corresponding $c_{p}(t)$ as the IMFs which contain the main fault information.

Then, the selected sensitive IMFs can be inputted into EDT. The algorithm is implemented by computing the Euclidean distances between the test sample and the trained sample as

$$
\begin{aligned}
D_{i j}^{2} & =\left(X_{i}-X_{j}\right)^{T}\left(X_{i}-X_{j}\right)=\left\|X_{i}-X_{j}\right\|^{2} \\
& =\sum_{p=1}^{P}\left(x_{i p}-x_{j p}\right)^{2},
\end{aligned}
$$

where $X_{i}$ is the test sample belonging to the unknown class and $X_{j}$ is the trained sample belonging to known class, class $\omega$. And $p=1,2, \ldots, P$ is the number of the selected IMFs.

Therefore, a feature parameter set $\left\{E_{m p q}, m=1,2, \ldots\right.$, $M ; p=1,2, \ldots, P ; q=1,2, \ldots, Q\}$ can be acquired before computing the Euclidean distances between the test samples and the trained samples, which is an $M$-by- $P$-by-Q matrix, where $m$ is the $m$ th crack level of gears, $p$ is the $p$ th IMF, and $q$ is the $q$ th test sample. Then the feature vector matrix can be built as

$$
\begin{array}{r}
T_{m q}=\left[E_{m q 1}, E_{m q 2}, \ldots, E_{m p q}\right], \\
m=1,2, \ldots, M \quad q=1,2, \ldots, Q .
\end{array}
$$

Euclidean distances between the test sample and trained samples can be calculated. If the distances between this test sample and each trained sample satisfy

$$
D^{2}\left(X, \omega_{i}\right)<D^{2}\left(X, \omega_{j}\right), \quad i, j=1,2, \ldots, M, i \neq j,
$$

then the test sample belongs to class $\omega$.

Following the procedure described above, the crack level classification of gears can be performed. The classification process can be summarized as follows.

(1) Acquire vibration signal.

(2) Obtain IMFs by signal processing and EMD.

(3) Select the sensitive IMFs which contain main fault information.

(4) Extract feature parameters of sensitive IMFs and build the feature vector matrix.

(5) Obtain the diagnosis result using EDT.

The flowchart of the new proposed method is described in Figure 1.

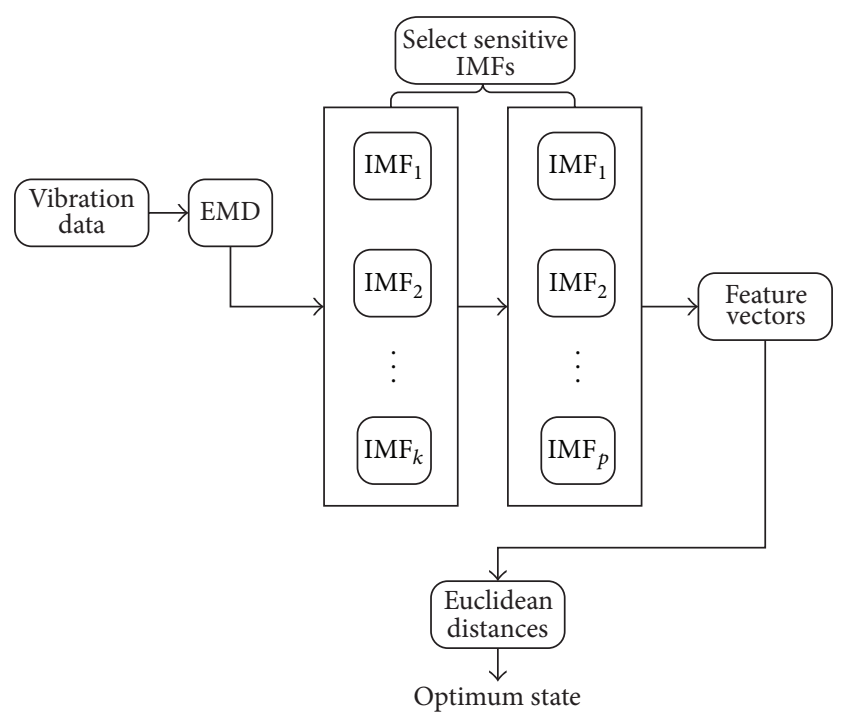

FIGURE 1: Flowchart of the classification process using EMD and EDT.

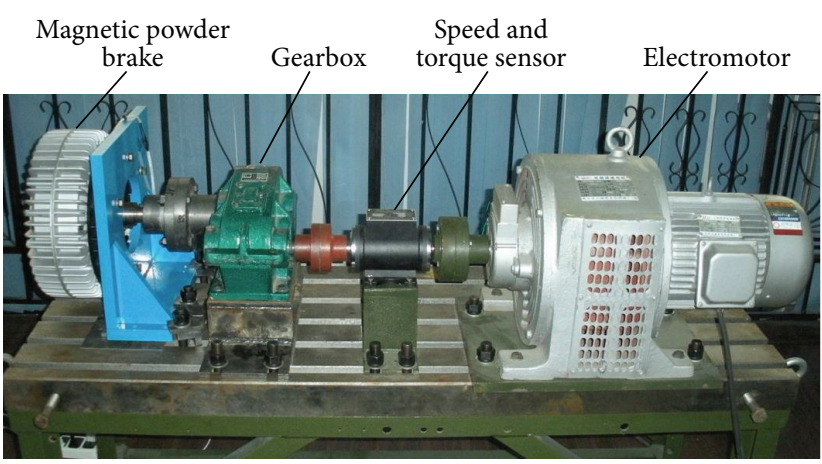

Figure 2: The gearbox test rig.

\section{A Case Study}

3.1. Experimental Setup and Data Acquisition. A mechanical test bed in the RCM laboratory of Mechanical Engineering College is used in this research to validate the effectiveness of the proposed method in this paper. The gearbox is driven by a $4 \mathrm{KW}$ three-phase asynchronous drive motor. In addition, the speed and torque sensors are used to acquire the speed and torque information; a magnetic powder brake is utilized to provide load. These components are connected by couplings, as shown in Figure 2.

The crack fault is implemented on one teeth of gear \#2. Three crack levels are introduced and the length of each level is $1 \mathrm{~mm}, 2 \mathrm{~mm}$, and $5 \mathrm{~mm}$, respectively. Figure 3 (a) shows the structure of the gearbox used in this experiment. Gear \#2 is the test gear and its tooth number is 64 . The tooth numbers of other three gears are 35 (\#1), 18 (\#3), and 81 (\#4), respectively. Four accelerometers are mounted on the gearbox casing and the specific location of every accelerometer is also shown in Figure 3(a). Figure 3(b) is the photo of the fault gear used in this study. 


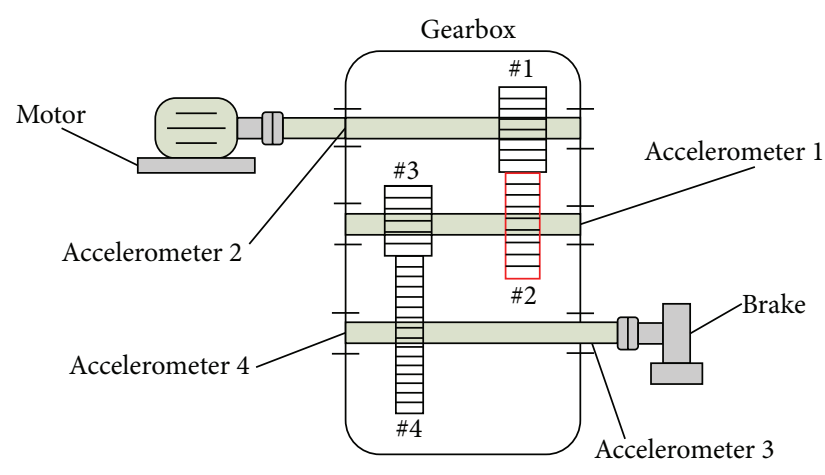

(a)

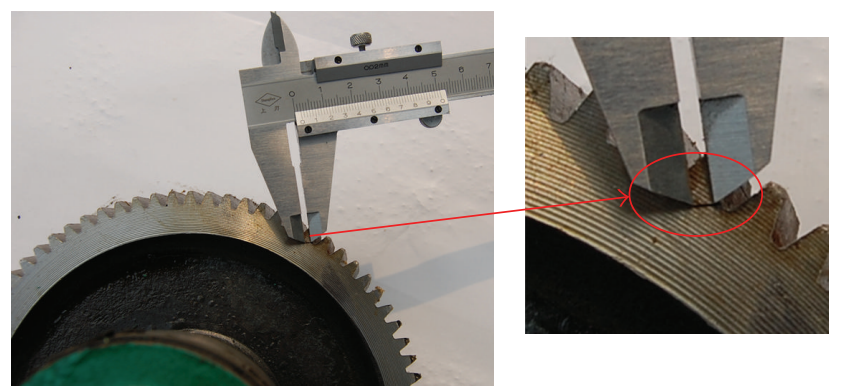

(b)

FIGURE 3: (a) The structure of the gearbox. (b) The fault gear used in this study.

The sampling frequency of this experimental system is $20 \mathrm{kHz}$ and sampling time is $6 \mathrm{~s}$. Each fault mode has 60 samples. The input rotary speed of motor is $800 \mathrm{rpm}$ and the loads generated by brake are $10 \mathrm{~N} \cdot \mathrm{m}, 15 \mathrm{~N} \cdot \mathrm{m}$, and $20 \mathrm{~N} \cdot \mathrm{m}$.

3.2. Results Analysis and Discussion. Following the procedure described in Section 2, the process of gear crack level classification can be introduced as follows. First, raw vibration data are collected from the data acquisition system of the gearbox test rig. This paper chooses the vibration data acquired by accelerometer 1 . Then, the vibration data is processed by EMD and a number of IMFs are obtained which range from 15 to 19. Taking one vibration signal which obtained 15 IMFs after processed by EMD as a sample, and the IMFs are shown in Figure 4.

In order to select the sensitive IMFs, the correlation coefficients and fault factors are calculated, which are shown in Table 1.

It can be seen from Table 1 that the first to sixth IMFs have great correlation of the fault signal and little correlation of the normal signal. Namely, these IMFs contain the main fault information, and they are selected as the sensitive IMFs.

The vibration signal of a gearbox is a mixture of many components, such as shafts and bearings, not limited to gear meshing vibration only. To validate the selected IMFs containing gear fault information, this paper analyzed the frequency spectrum of original signal and each IMF, respectively. The signal is acquired from $1 \mathrm{~mm}$ crack state with $800 \mathrm{rpm}$ speed and $20 \mathrm{Nm}$ load condition.

Usually, shaft and bearing rotating frequencies are all in low frequency area. And gear meshing frequency will be a little high relatively. Figure 5 is the envelope analysis of original signal. The figure shows that gear meshing frequencies are very obvious. Shafts and bearings rotating frequencies can also be seen in low frequency area. In addition, the noise pollution is very serious.

Figure 6 is the envelope analysis of $\mathrm{IMF}_{1}$. Similarly, gear meshing and shafts and bearings rotating frequencies are obvious. But the noise pollution is restrained effectively. Figure 7 is the envelope analysis of $\mathrm{IMF}_{2}$. It can be seen
TABLE 1: The correlation coefficients and fault factor of IMFs.

\begin{tabular}{lccc}
\hline Number & $\alpha_{k}$ & $\beta_{k}$ & $\lambda_{k}$ \\
\hline IMF1 & 0.471 & 0.001 & 0.470 \\
IMF2 & 0.494 & -0.007 & 0.501 \\
IMF3 & 0.556 & 0.012 & 0.543 \\
IMF4 & 0.384 & -0.012 & 0.396 \\
IMF5 & 0.285 & 0.001 & 0.284 \\
IMF6 & 0.154 & 0.000 & 0.154 \\
IMF7 & 0.028 & -0.004 & 0.032 \\
IMF8 & 0.005 & 0.000 & 0.005 \\
IMF9 & 0.006 & 0.002 & 0.004 \\
IMF10 & 0.017 & 0.005 & 0.013 \\
IMF11 & 0.011 & -0.005 & 0.016 \\
IMF12 & 0.000 & 0.000 & 0.000 \\
IMF13 & 0.001 & 0.000 & 0.000 \\
IMF14 & 0.000 & 0.000 & -0.001 \\
IMF15 & -0.001 & 0.000 & -0.001 \\
\hline
\end{tabular}

from the figure that gear meshing frequencies are prominent. However, shafts and bearings rotating frequencies are filtered out. Because the filtered order of EMD is from high frequency to low, so these results can ensure that the selected IMFs contain gear fault information.

Then, the feature parameter vectors can be calculated. This paper selects energy of IMF as feature parameter. In addition, the gear has 4 crack levels and 30 test samples are chosen for each crack level. So, the energy set, $E_{m p q}$, is a 4by-6-by-30 matrix. The mean values of feature vectors of all the samples for the same class are used as the trained sample. Therefore, the euclidean distances between test samples and four classess trained samples can be obtained. Table 2 shows the distance values between normal test samples and the trained samples of each level when the load is $10 \mathrm{~N} \cdot \mathrm{m}$. It can be seen from Table 2 that distance values between test samples and the trained samples of normal state are the minimum, and the accuracy rate of the classification result is about $96.67 \%$. 


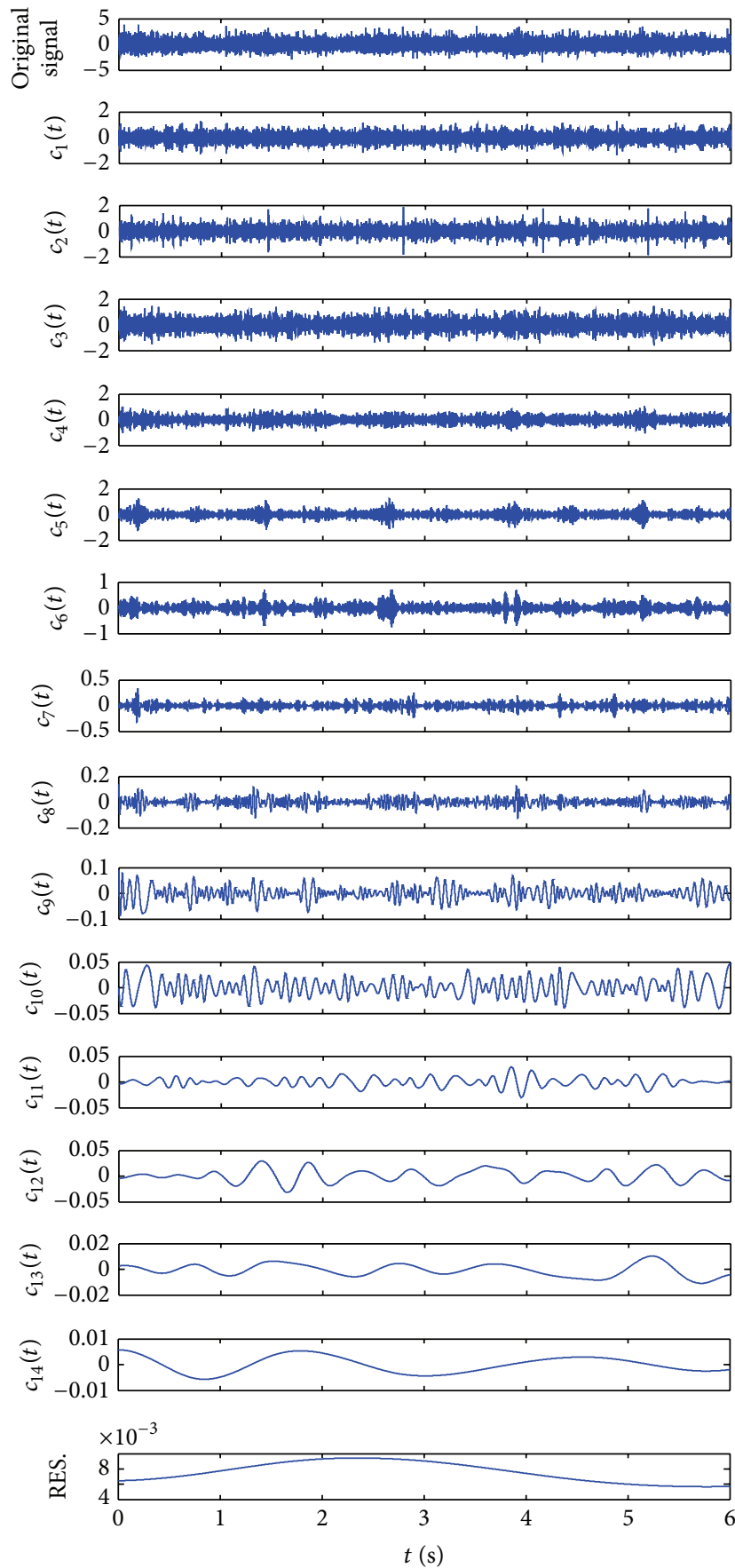

FIgURE 4: The decomposition result by EMD.

To show the distance values more directly and save space, the results are all shown by figures. When the load is $10 \mathrm{~N} \cdot \mathrm{m}$, the results can be depicted as in Figures 8, 9, 10, and 11. It can be seen from the figures that the accuracy rate of the classification results using the proposed method is approximately $100 \%$.

To validate the effectiveness of EMD, the energy of original signal that is not processed by EMD is extracted and the classification results are shown as in Figures 12, 13, 14, and 15 . It can be seen that for the case that the energy of
TABLE 2: The distance values when normal test samples are inputted and the load is $10 \mathrm{~N} \cdot \mathrm{m}$.

\begin{tabular}{lcccc}
\hline Number & Normal & $1 \mathrm{~mm}$ crack & $2 \mathrm{~mm}$ crack & $5 \mathrm{~mm}$ crack \\
\hline 1 & $\mathbf{2 . 3 8 E}+\mathbf{0 3}$ & $1.30 E+04$ & $4.94 E+03$ & $1.12 E+04$ \\
2 & $\mathbf{2 . 1 4 E}+\mathbf{0 3}$ & $1.32 E+04$ & $5.41 E+03$ & $1.15 E+04$ \\
3 & $\mathbf{1 . 8 1 E}+\mathbf{0 3}$ & $1.39 E+04$ & $7.28 E+03$ & $1.25 E+04$ \\
4 & $\mathbf{1 . 9 8 E}+\mathbf{0 3}$ & $1.20 E+04$ & $6.09 E+03$ & $1.05 E+04$ \\
5 & $\mathbf{1 . 7 9 E}+\mathbf{0 3}$ & $1.39 E+04$ & $7.98 E+03$ & $1.26 E+04$ \\
6 & $\mathbf{2 . 0 6 E}+\mathbf{0 3}$ & $1.38 E+04$ & $6.28 E+03$ & $1.23 E+04$ \\
7 & $\mathbf{2 . 6 4 E}+\mathbf{0 3}$ & $1.38 E+04$ & $8.10 E+03$ & $1.25 E+04$ \\
8 & $\mathbf{1 . 9 4 E}+\mathbf{0 3}$ & $1.38 E+04$ & $6.21 E+03$ & $1.22 E+04$ \\
9 & $\mathbf{2 . 4 3 E}+\mathbf{0 3}$ & $1.33 E+04$ & $6.92 E+03$ & $1.18 E+04$ \\
10 & $\mathbf{2 . 6 5 E}+\mathbf{0 3}$ & $1.42 E+04$ & $6.73 E+03$ & $1.25 E+04$ \\
11 & $\mathbf{1 . 8 9 E}+\mathbf{0 3}$ & $1.34 E+04$ & $5.37 E+03$ & $1.16 E+04$ \\
12 & $\mathbf{1 . 6 6 E}+\mathbf{0 3}$ & $1.45 E+04$ & $7.72 E+03$ & $1.30 E+04$ \\
13 & $\mathbf{1 . 9 0 E}+\mathbf{0 3}$ & $1.34 E+04$ & $6.19 E+03$ & $1.17 E+04$ \\
14 & $\mathbf{3 . 4 0 E}+\mathbf{0 3}$ & $1.49 E+04$ & $8.77 E+03$ & $1.35 E+04$ \\
15 & $\mathbf{1 . 3 3 E}+\mathbf{0 3}$ & $1.40 E+04$ & $7.71 E+03$ & $1.25 E+04$ \\
16 & $\mathbf{1 . 6 4 E}+\mathbf{0 3}$ & $1.38 E+04$ & $7.10 E+03$ & $1.22 E+04$ \\
17 & $\mathbf{2 . 2 9 E}+\mathbf{0 3}$ & $1.39 E+04$ & $5.83 E+03$ & $1.21 E+04$ \\
18 & $\mathbf{2 . 4 3 E + 0 3}$ & $1.40 E+04$ & $6.34 E+03$ & $1.23 E+04$ \\
19 & $\mathbf{1 . 9 8 E + 0 3}$ & $1.33 E+04$ & $6.45 E+03$ & $1.18 E+04$ \\
20 & $\mathbf{1 . 8 8 E}+\mathbf{0 3}$ & $1.45 E+04$ & $6.89 E+03$ & $1.28 E+04$ \\
21 & $\mathbf{2 . 5 4 E}+\mathbf{0 3}$ & $1.45 E+04$ & $6.92 E+03$ & $1.29 E+04$ \\
22 & $\mathbf{3 . 9 9 E}+\mathbf{0 3}$ & $1.53 E+04$ & $8.91 E+03$ & $1.40 E+04$ \\
23 & $4.40 E+03$ & $1.37 E+04$ & $\mathbf{4 . 1 6 E}+\mathbf{0 3}$ & $1.16 E+04$ \\
24 & $\mathbf{2 . 9 7 E + 0 3}$ & $1.43 E+04$ & $5.99 E+03$ & $1.25 E+04$ \\
25 & $\mathbf{3 . 2 3 E + 0 3}$ & $1.42 E+04$ & $6.73 E+03$ & $1.25 E+04$ \\
26 & $\mathbf{4 . 7 8 E + 0 3}$ & $1.42 E+04$ & $5.33 E+03$ & $1.22 E+04$ \\
27 & $\mathbf{3 . 9 1 E}+\mathbf{0 3}$ & $1.37 E+04$ & $5.24 E+03$ & $1.18 E+04$ \\
28 & $\mathbf{3 . 1 6 E}+\mathbf{0 3}$ & $1.41 E+04$ & $6.63 E+03$ & $1.23 E+04$ \\
29 & $\mathbf{4 . 6 6 E}+\mathbf{0 3}$ & $1.48 E+04$ & $6.45 E+03$ & $1.31 E+04$ \\
30 & $\mathbf{3 . 3 9 E}+\mathbf{0 3}$ & $1.37 E+04$ & $5.40 E+03$ & $1.17 E+04$ \\
\hline & & & &
\end{tabular}

original signal is extracted without EMD the accuracy rate is about $80 \%$ and the classification results are unsatisfactory. Therefore, the process of EMD is effective by this comparing study.

In order to validate the proposed method for which sensitive IMFs are selected, energy of first to third IMFs is extracted and the final classification results are shown as in Figures 16, 17, 18, and 19. The classification results show the effectiveness of the proposed method for selecting the sensitive IMFs. If all IMFs are selected, the computing velocity will be slow. And if few IMFs are selected, for the case of 3 IMFs, the classification results will be not very accurate.

All the samples above are under the load of $10 \mathrm{~N} \cdot \mathrm{m}$; for the purpose of checking the adaptability to different conditions of the method, the load of $15 \mathrm{~N} \cdot \mathrm{m}$ and $20 \mathrm{~N} \cdot \mathrm{m}$ is also considered and the classification results are shown as in Figures 20, 21, 22, and 23 and Figures 24, 25, 26, and 27, respectively. It can be seen that the method proposed in this paper also has good performance. The accuracy rates are nearly $100 \%$ for the two cases. 


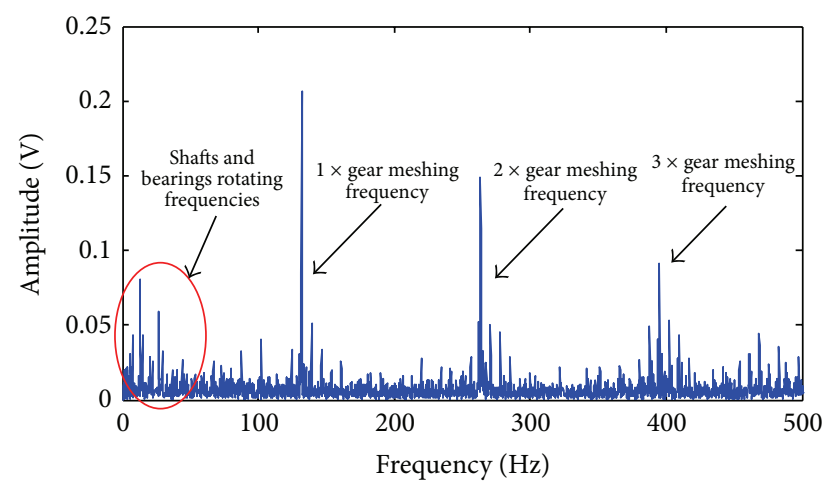

FIGURE 5: Envelope analysis of original signal.

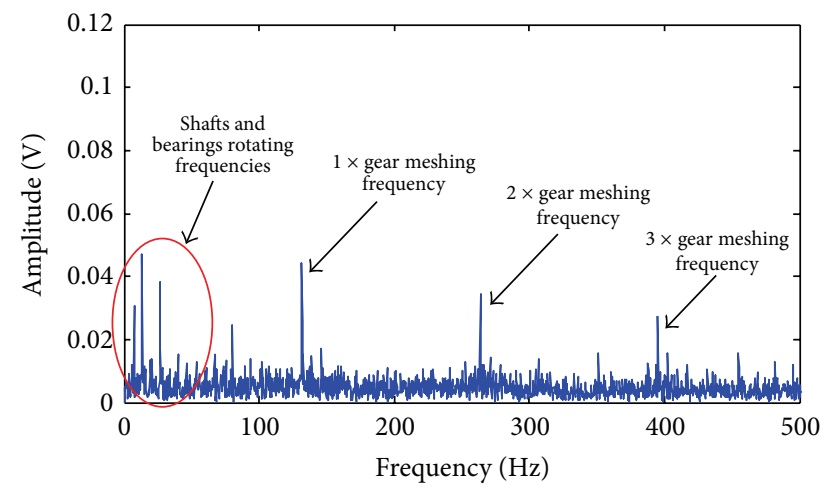

Figure 6: Envelope analysis of $\mathrm{IMF}_{1}$.

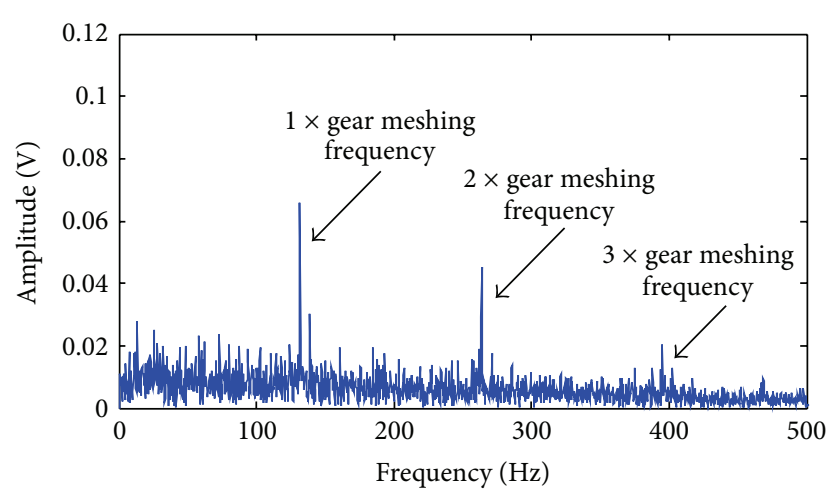

Figure 7: Envelope analysis of $\mathrm{IMF}_{2}$.

It can be obtained from above analysis that the gear crack level classification method is effective to identify different crack levels no matter whether the fault is in early stage $(1 \mathrm{~mm})$ or sever stage $(5 \mathrm{~mm})$. In addition, EMD and the method of selecting sensitive IMFs are crucial during process of the original signal.

\section{Conclusion}

In this paper, a new gear crack level classification method based on empirical mode decomposition (EMD) and Euclidean distance technique (EDT) is proposed. The approach was

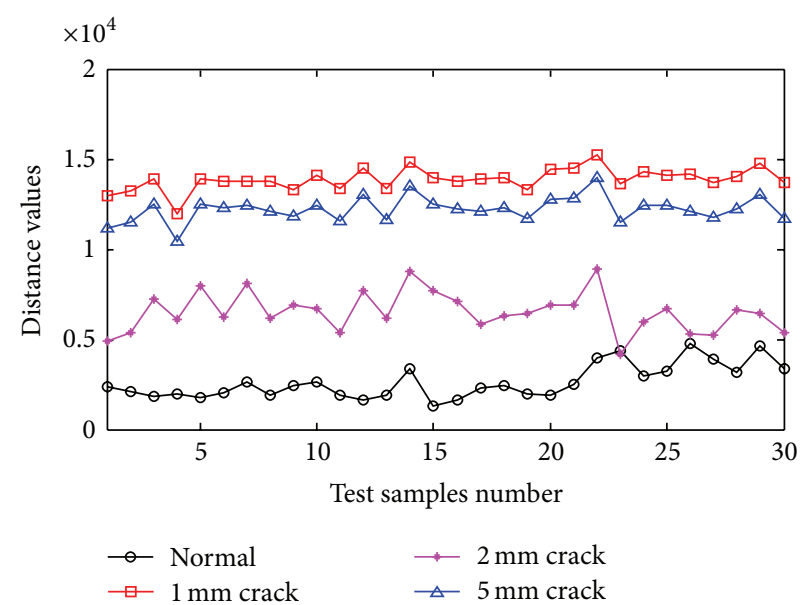

FIGURE 8: The classification result when normal test samples are inputted.

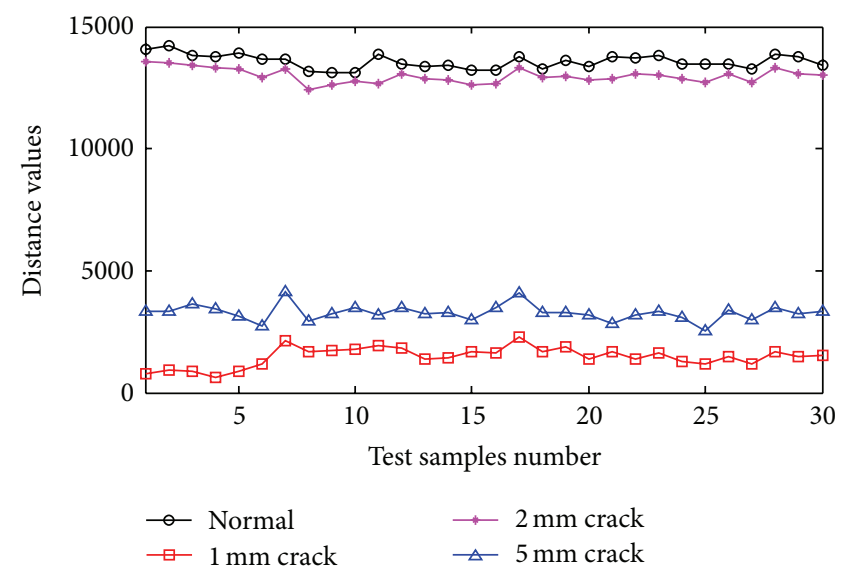

FIGURE 9: The classification result when $1 \mathrm{~mm}$ crack test samples are inputted.

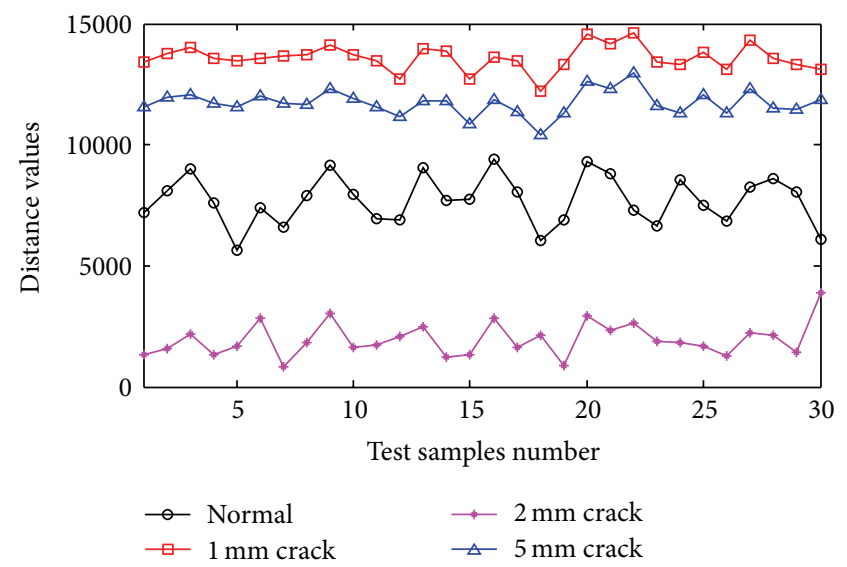

FIgURE 10: The classification result when $2 \mathrm{~mm}$ crack test samples are inputted. 


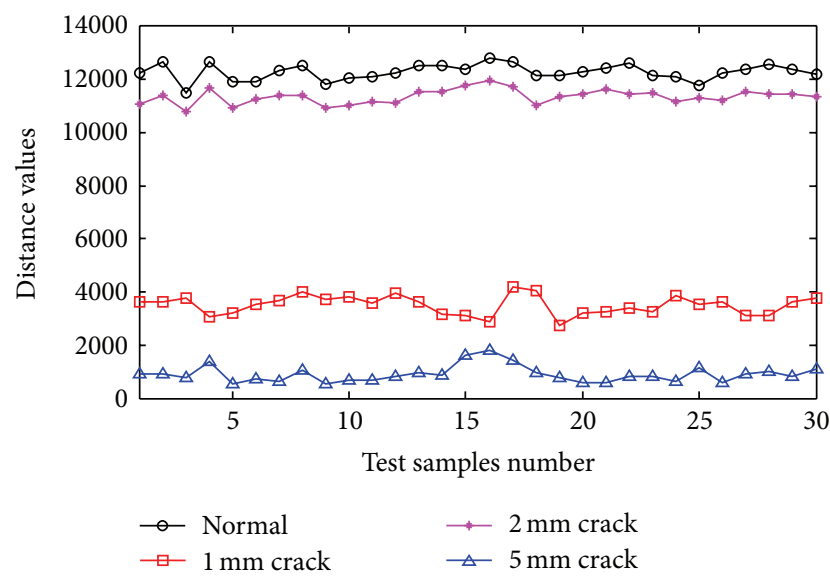

FIgURE 11: The classification result when $5 \mathrm{~mm}$ crack test samples areinputted.

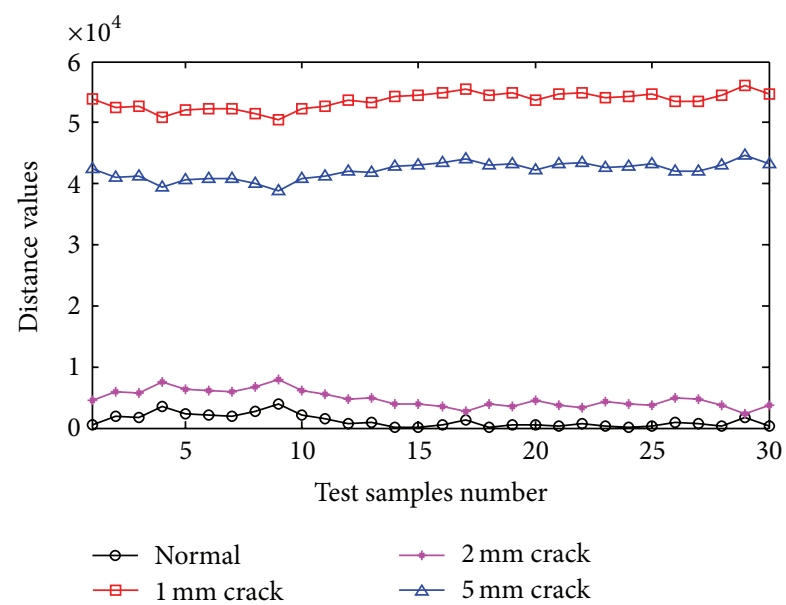

FIGURE 12: The classification result of original signal when normal test samples are inputted.

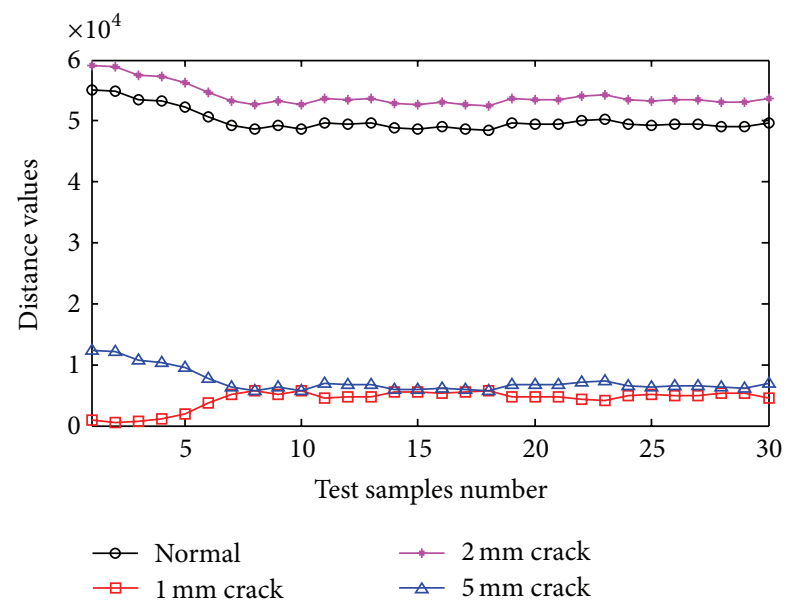

FIGURE 13: The classification result of original signal when $1 \mathrm{~mm}$ crack test samples are inputted.

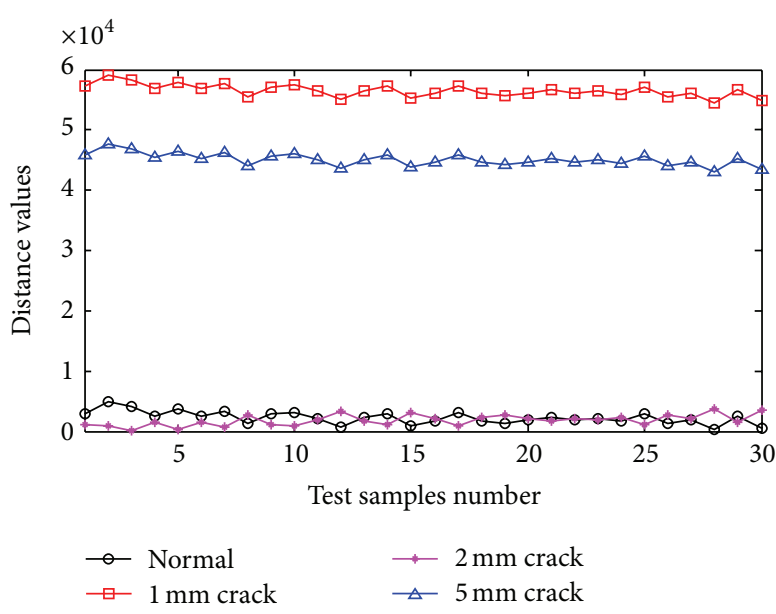

FIgURE 14: The classification result of original signal when $2 \mathrm{~mm}$ crack test samples are inputted.

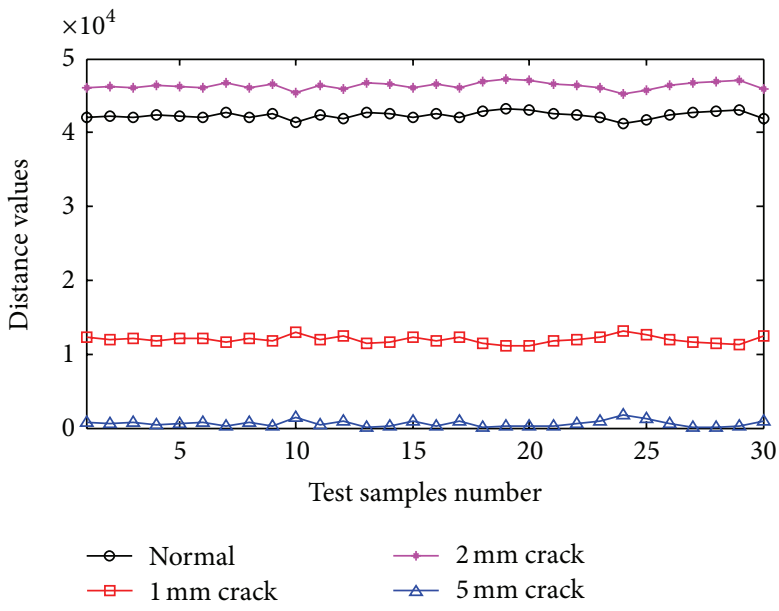

FIgURE 15: The classification result of original signal when $5 \mathrm{~mm}$ crack test samples are inputted.

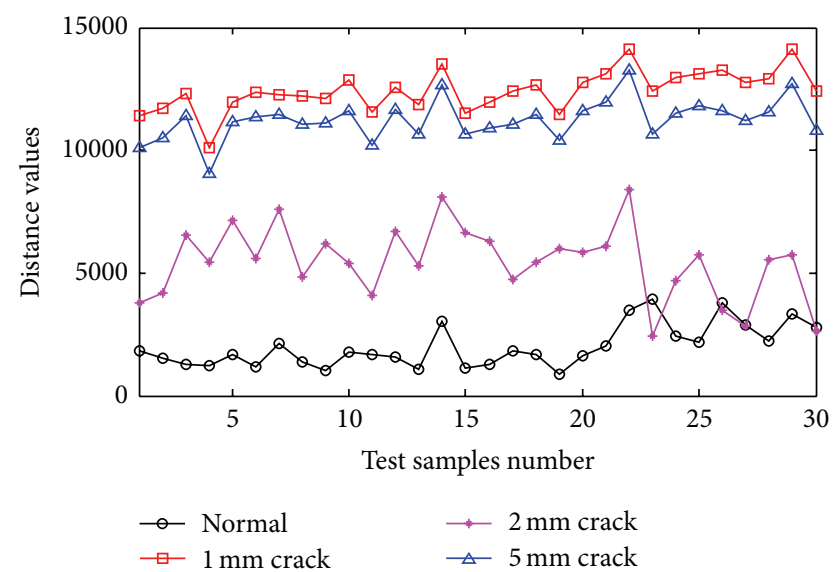

FIgURE 16: The classification result using first to third IMFs when normal test samples are inputted. 


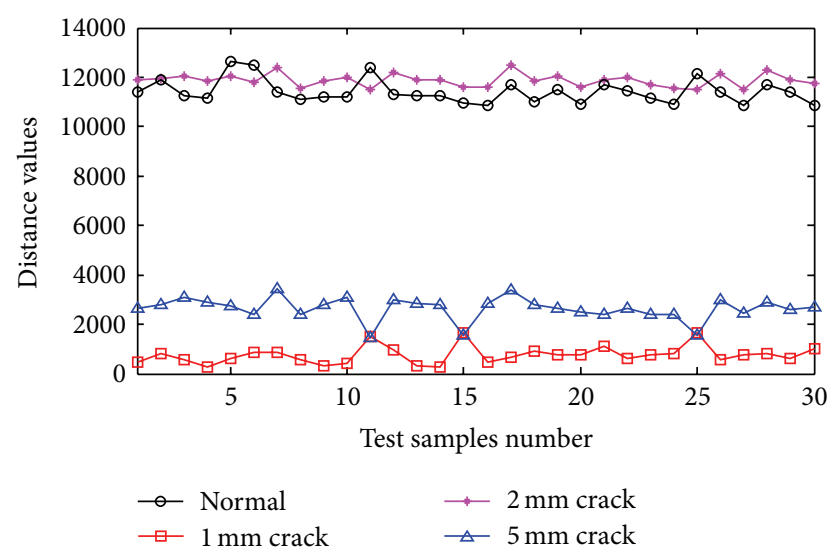

Figure 17: The classification result using first to third IMFs when $1 \mathrm{~mm}$ crack test samples are inputted.

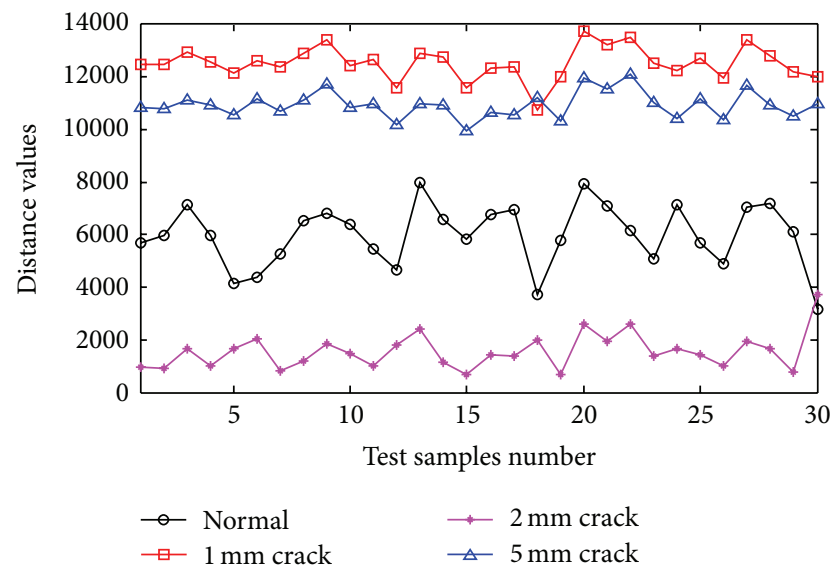

FIGURE 18: The classification result using first to third IMFs when $2 \mathrm{~mm}$ crack test samples are inputted.

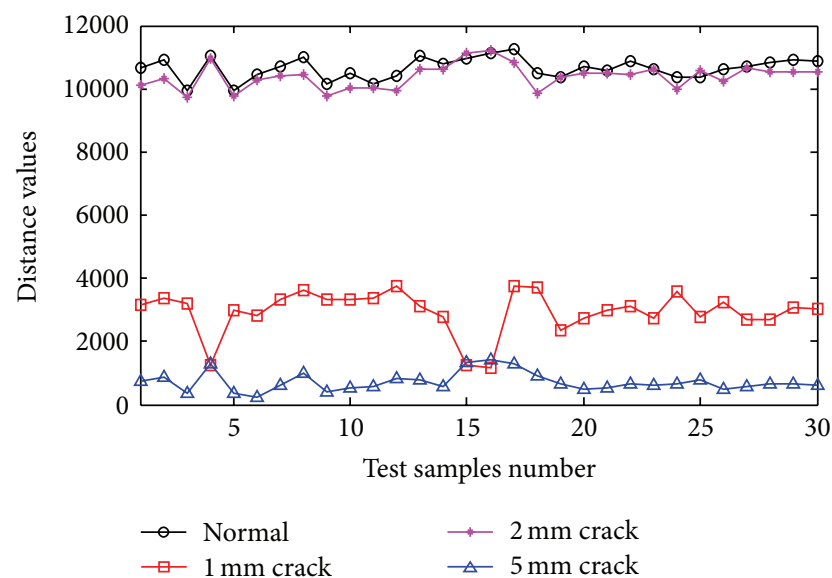

FIGURE 19: The classification result using first to third IMFs when $5 \mathrm{~mm}$ crack test samples are inputted.

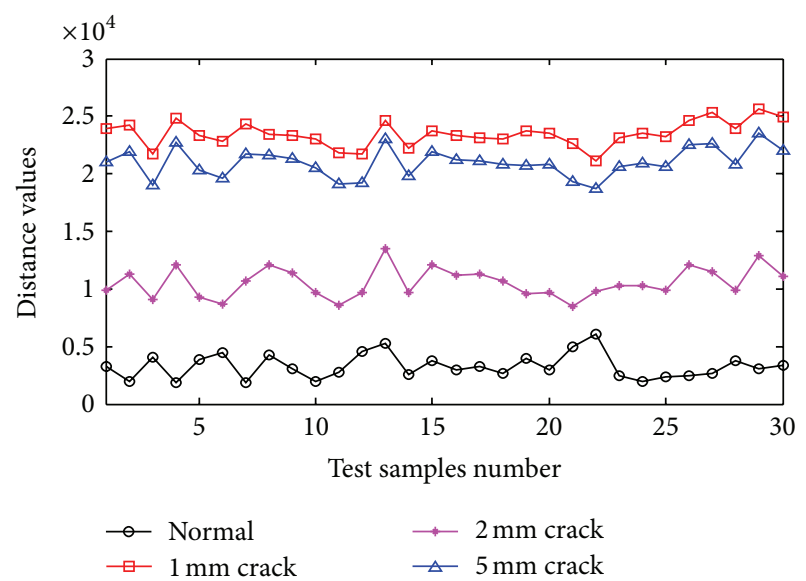

FIGURE 20: The classification result of $15 \mathrm{~N} \cdot \mathrm{m}$ load when normal test samples are inputted.

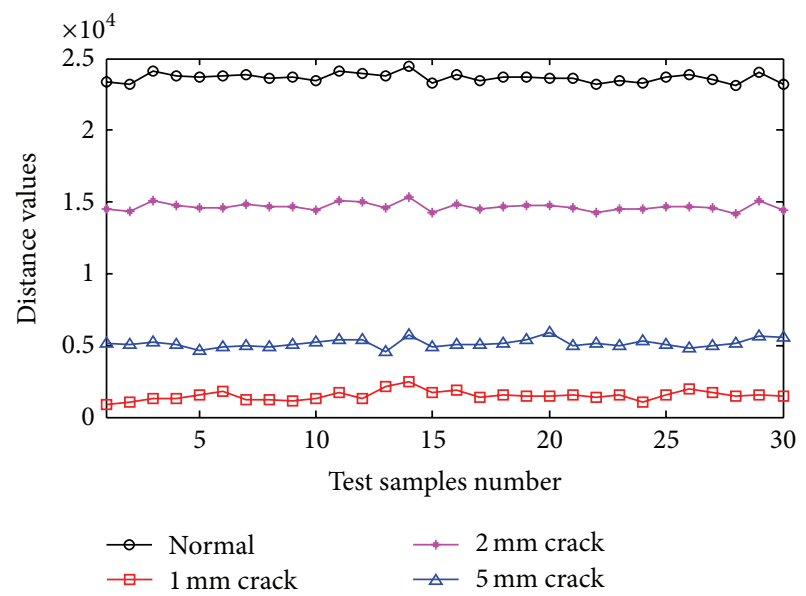

FIgURE 21: The classification result of $15 \mathrm{~N} \cdot \mathrm{m}$ load when $1 \mathrm{~mm}$ crack test samples are inputted.

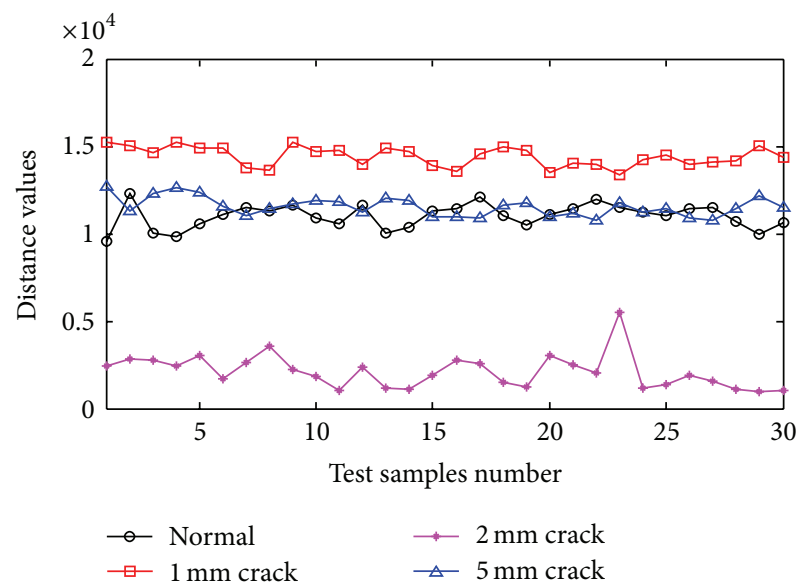

FIGURE 22: The classification result of $15 \mathrm{~N} \cdot \mathrm{m}$ load when $2 \mathrm{~mm}$ crack test samples are inputted. 


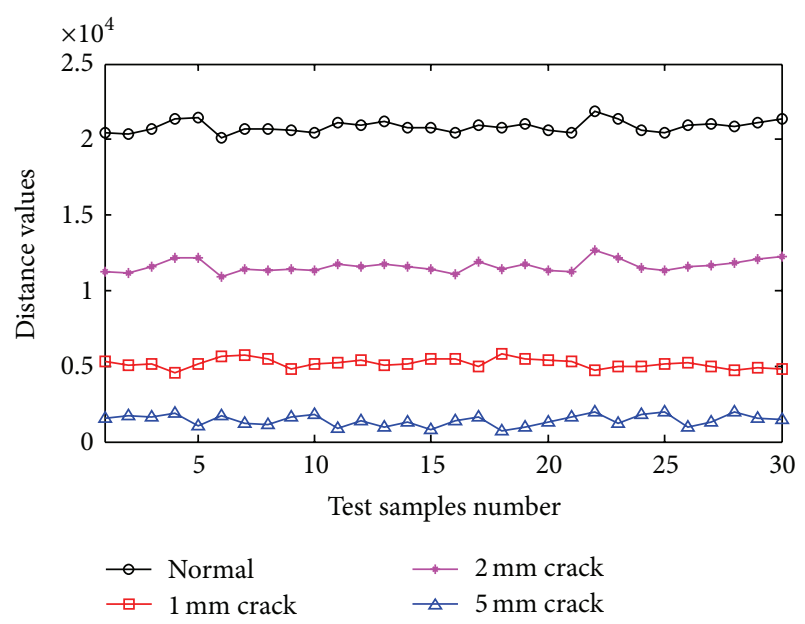

FIgURE 23: The classification result of $15 \mathrm{~N} \cdot \mathrm{m}$ load when $2 \mathrm{~mm}$ crack test samples are inputted.

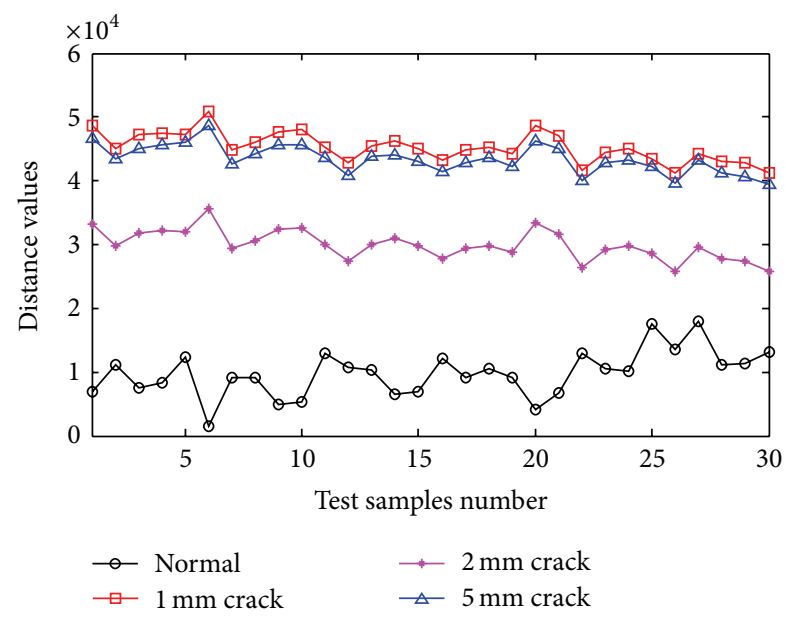

FIGURE 24: The classification result of $20 \mathrm{~N} \cdot \mathrm{m}$ load when normal test samples are inputted.

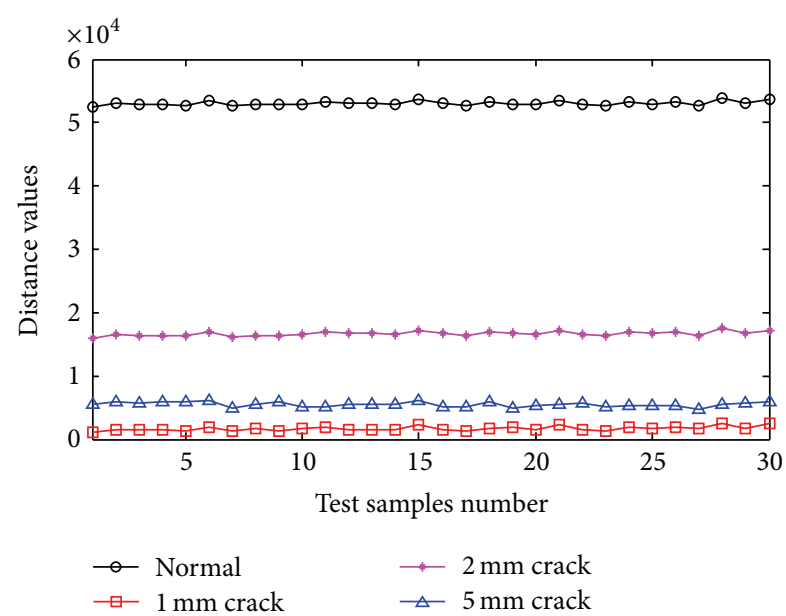

FIGURE 25: The classification result of $20 \mathrm{~N} \cdot \mathrm{m}$ load when $1 \mathrm{~mm}$ crack test samples are inputted.

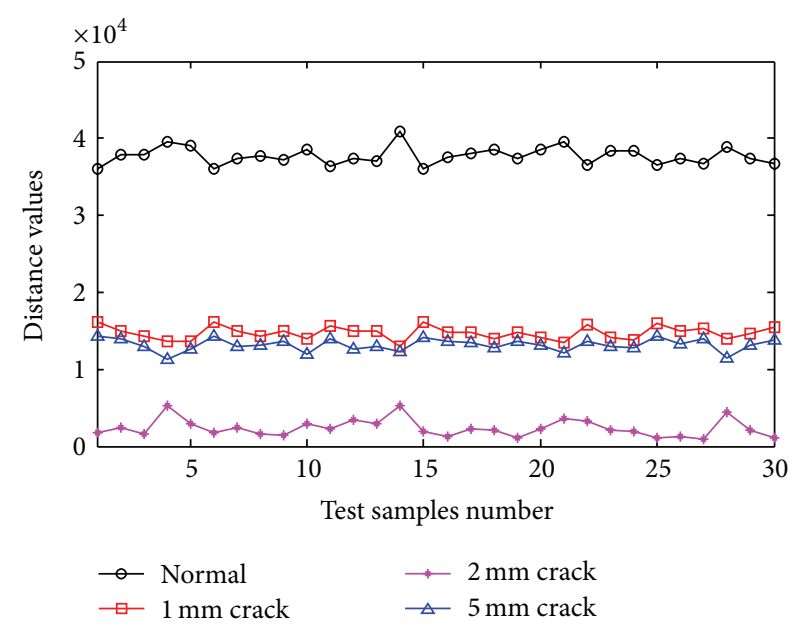

FIgURE 26: The classification result of $20 \mathrm{~N} \cdot \mathrm{m}$ load when $2 \mathrm{~mm}$ crack test samples are inputted.

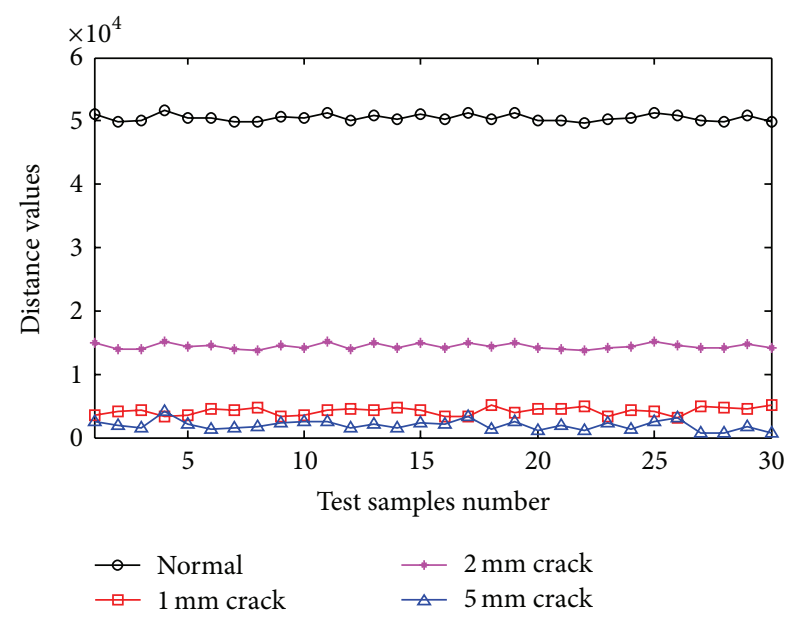

FIgURE 27: The classification result of $20 \mathrm{~N} \cdot \mathrm{m}$ load when $5 \mathrm{~mm}$ crack test samples are inputted.

tested and validated successfully using a test rig implanted crack fault experiment case. The results show the proposed method obtains high accuracy rate in classifying different crack levels and adapts to different conditions. Additionly, it is found through comparison that EMD and the method of selecting sensitive IMFs are crucial during process of the original signal.

\section{Conflict of Interests}

The authors declare that there is no conflict of interests regarding the publication of this paper.

\section{References}

[1] A. K. S. Jardine, D. Lin, and D. Banjevic, "A review on machinery diagnostics and prognostics implementing condition-based maintenance," Mechanical Systems and Signal Processing, vol. 20, no. 7, pp. 1483-1510, 2006. 
[2] P. D. Samuel and D. J. Pines, "A review of vibration-based techniques for helicopter transmission diagnostics," Journal of Sound and Vibration, vol. 282, no. 1-2, pp. 475-508, 2005.

[3] M. Lebold, K. McClintic, R. Campbell et al., "Review of vibration analysis methods for gearbox diagnostics and prognostics," in Proceedings of the 54th Meeting of the Society for Machinery Failure Prevention Technology, pp. 623-634, 2000.

[4] P. D. Samuel and D. J. Pines, "Vibration separation methodology for planetary gear health monitoring," in Proceeding of SPIE, vol. 3985, pp. 250-260, March 2000.

[5] P. D. McFadden, "A technique for calculating the time domain averages of the vibration of the individual planet gears and the sun gear in an epicyclic gearbox," Journal of Sound and Vibration, vol. 144, no. 1, pp. 163-172, 1991.

[6] P. D. McFadden, "Window functions for the calculation of the time domain averages of the vibration of the individual planet gears and sun gear in an epicyclic gearbox," Journal of Vibration and Acoustics, Transactions of the ASME, vol. 116, no. 2, pp. 179187, 1994.

[7] E. B. Halim, M. A. A. Shoukat Choudhury, S. L. Shah, and M. J. Zuo, "Time domain averaging across all scales: a novel method for detection of gearbox faults," Mechanical Systems and Signal Processing, vol. 22, no. 2, pp. 261-278, 2008.

[8] Z. P. Feng, M. J. Zuo, and F. L. Chu, "Application of regularization dimension to gear damage assessment," Mechanical Systems and Signal Processing, vol. 24, no. 4, pp. 1081-1098, 2010.

[9] X. Zhang, J. Kang, E. Bechhoefer, and J. Zhao, "A new feature extraction method for gear fault diagnosis and prognosis," Maintenance and Reliability, vol. 16, no. 2, pp. 295-300, 2014.

[10] X. H. Zhang, J. S. Kang, E. Bechhoefer, L. Xiao, and J. M. Zhao, "Gearbox degradation analysis using narrowband interference cancellation under non-stationary conditions," Journal of Vibroengineering, vol. 16, no. 4, pp. 2089-2102, 2014.

[11] L. M. R. Baccarini, V. V. Rocha E Silva, B. R. De Menezes, and W. M. Caminhas, "SVM practical industrial application for mechanical faults diagnostic," Expert Systems with Applications, vol. 38, no. 6, pp. 6980-6984, 2011.

[12] X. L. Tang, L. Zhuang, J. Cai, and C. B. Li, "Multi-fault classification based on support vector machine trained by chaos particle swarm optimization," Knowledge-Based Systems, vol. 23, no. 5, pp. 486-490, 2010.

[13] G. G. Yen and W. F. Leong, "Fault classification on vibration data with wavelet based feature selection scheme," ISA Transactions, vol. 45, no. 2, pp. 141-151, 2006.

[14] X. H. Zhang, L. Xiao, and J. S. Kang, "Application of an improved Levenberg-Marquardt back propagation neural network to gear fault level identification," Journal of Vibroengineering, vol. 16, no. 2, pp. 855-868, 2014.

[15] T. Boutros and M. Liang, "Detection and diagnosis of bearing and cutting tool faults using hidden Markov models," Mechanical Systems and Signal Processing, vol. 25, no. 6, pp. 2102-2124, 2011.

[16] J. S. Kang and X. H. Zhang, "Application of hidden markov models in machine fault diagnosis," Information-An International Interdisciplinary Journal, vol. 15, no. 12, pp. 5829-5838, 2012.

[17] S. Hassiotis, "Identification of damage using natural frequencies and Markov parameters," Computers and Structures, vol. 74, no. 3, pp. 365-373, 2000.

[18] X. Fan and M. J. Zuo, "Gearbox fault detection using Hilbert and wavelet packet transform," Mechanical Systems and Signal Processing, vol. 20, no. 4, pp. 966-982, 2006.
[19] S. J. Loutridis, "Instantaneous energy density as a feature for gear fault detection," Mechanical Systems and Signal Processing, vol. 20, no. 5, pp. 1239-1253, 2006.

[20] S. J. Loutridis, "Self-similarity in vibration time series: application to gear fault diagnostics," Journal of Vibration and Acoustics, Transactions of the ASME, vol. 130, no. 3, Article ID 031004, 2008.

[21] Y. Lei and M. J. Zuo, "Gear crack level identification based on weighted K nearest neighbor classification algorithm," Mechanical Systems and Signal Processing, vol. 23, no. 5, pp. 1535-1547, 2009.

[22] N. E. Huang, Z. Shen, S. R. Long et al., "The empirical mode decomposition and the Hilbert spectrum for nonlinear and non-stationary time series analysis," Proceeding of the Royal Society of London Series A, vol. 454, no. 1971, pp. 903-995, 1998.

[23] L. Hui, Y. Zhang, and H. Zheng, "Wear detection in gear system using Hilbert-Huang transform," Journal of Mechanical Science and Technology, vol. 20, no. 11, pp. 1781-1789, 2006.

[24] Z. P. Feng and F. L. Chu, "Transient hydraulic pressure fluctuation signal analysis of hydroturbine based on Hilbert-huang transform," Proceedings of the CSEE, vol. 25, no. 10, pp. 111-115, 2005.

[25] Z. P. Feng, X. J. Li, and F. L. Chu, "Application of stationary wavelet packets decomposition based hilbert spectrum to nonstationary hydraulic turbine vibration signal analysis," Proceedings of the Chinese Society of Electrical Engineering, vol. 26, no. 12, pp. 79-84, 2006.

[26] Z. Feng and F. Chu, "Frequency demodulation analysis method for fault diagnosis of planetary gearboxes," Proceedings of the Chinese Society of Electrical Engineering, vol. 33, no. 11, pp. 112117, 2013. 


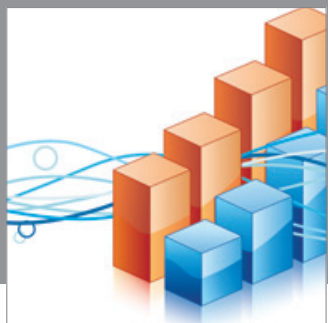

Advances in

Operations Research

mansans

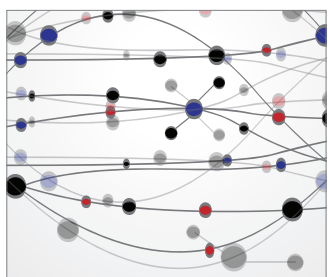

The Scientific World Journal
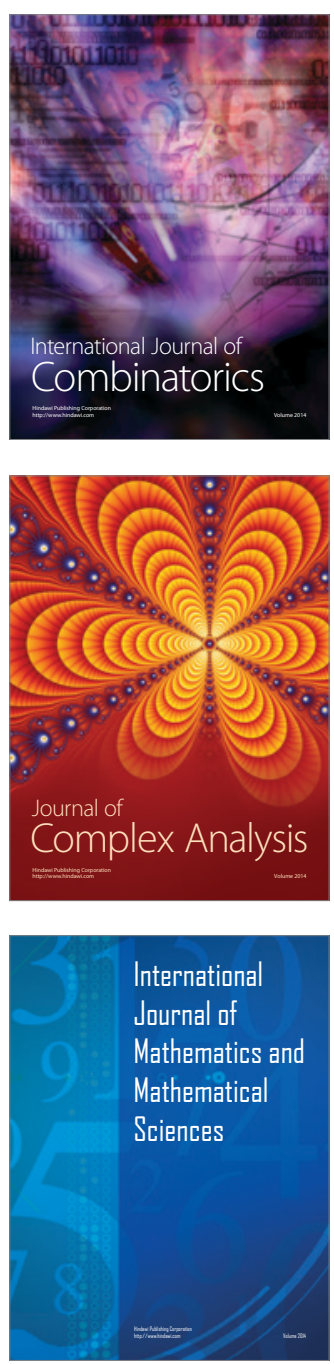
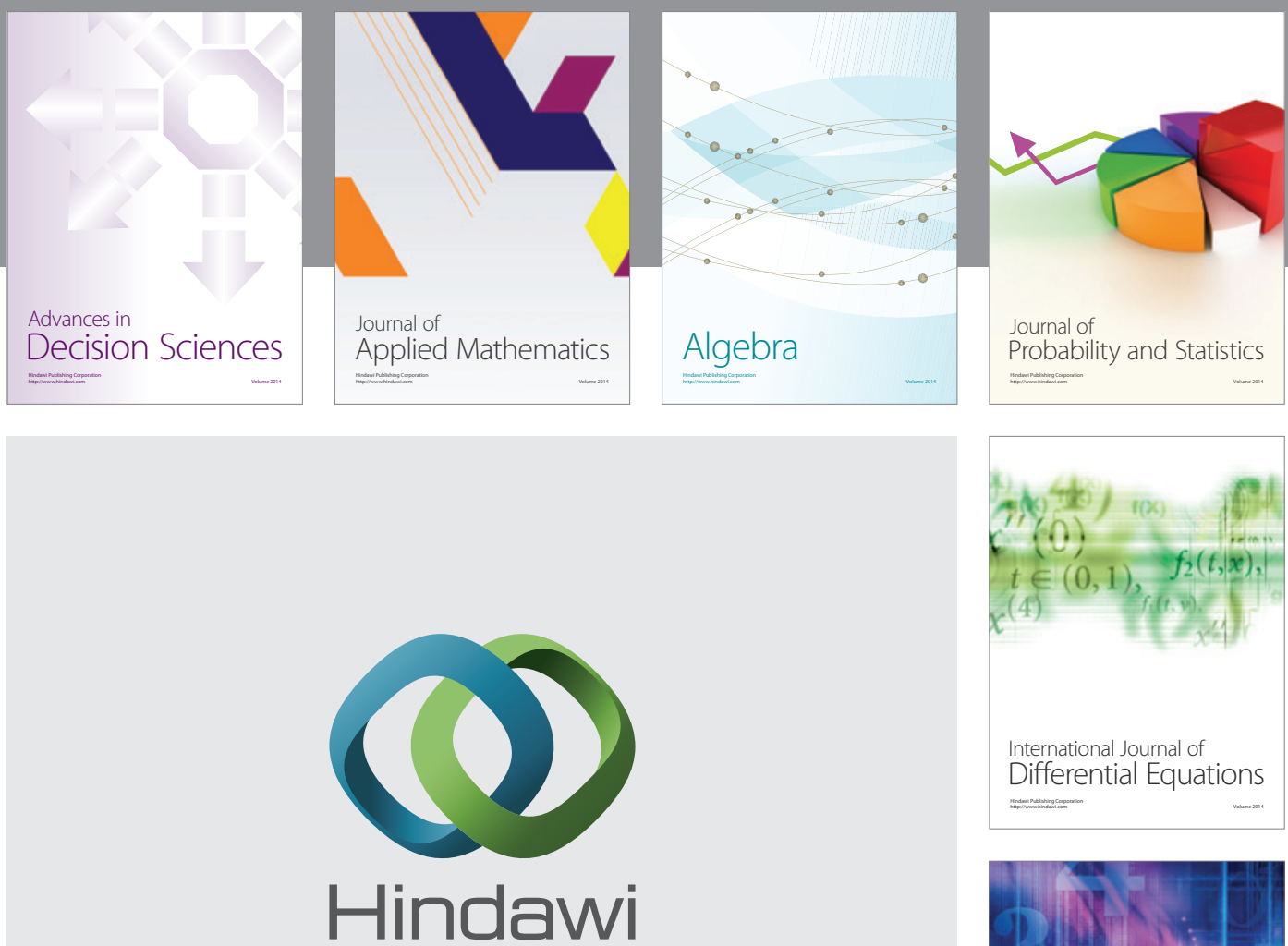

Submit your manuscripts at http://www.hindawi.com
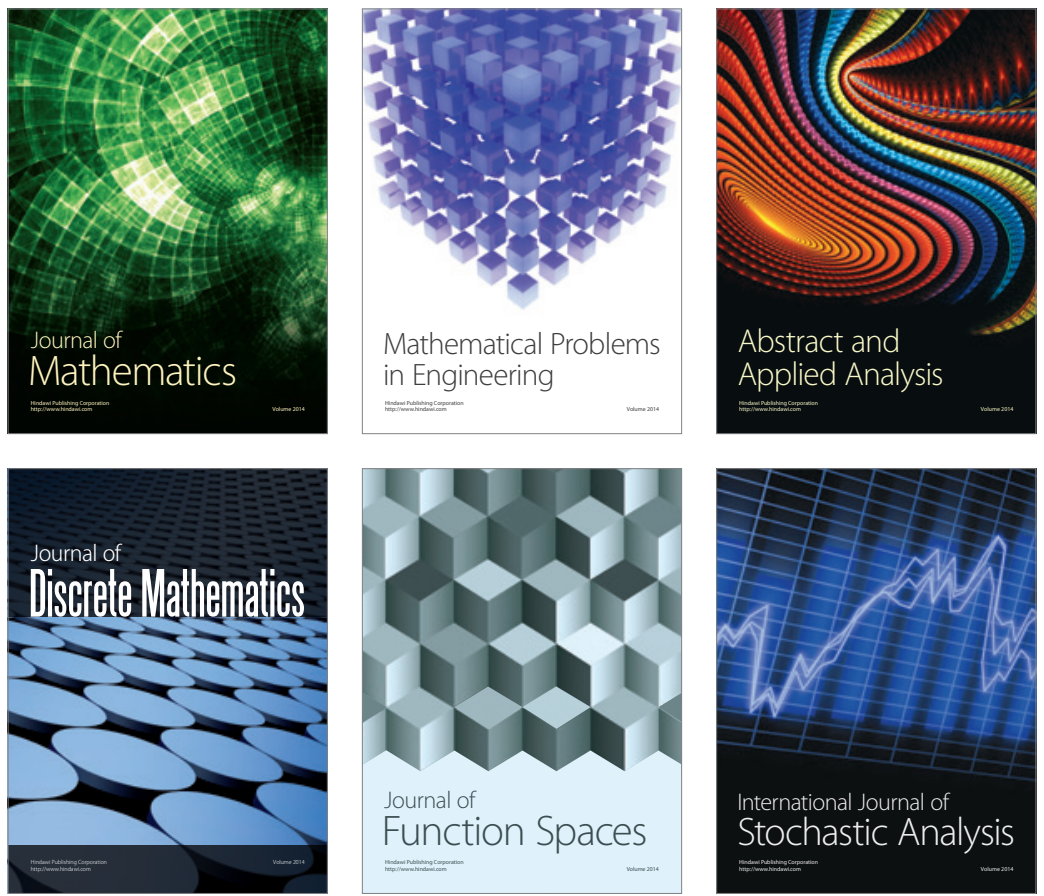

Journal of

Function Spaces

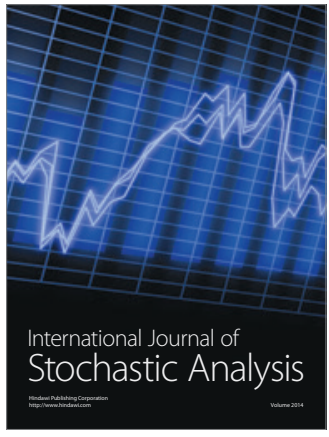

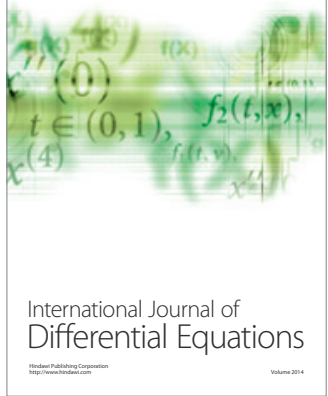
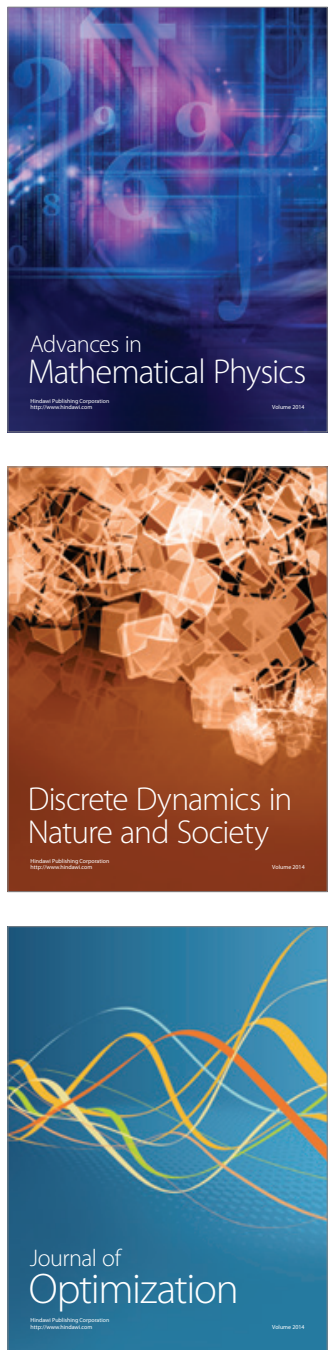